\title{
La pintura mural tardogótica en la provincia de Valladolid: iglesia de San Bartolomé de Fompedraza
}

\author{
Sergio NúÑEZ MoRCILlO \\ Departamento de Historia del Arte \\ Facultad de Filosofía y Letras \\ Universidad de Valladolid \\ sergioarte84@hotmail.com
}

\section{RESUMEN}

Mediante este artículo sobre las pinturas murales de la iglesia de San Bartolomé de Fompedraza, localidad ubicada al este de la provincia de Valladolid, no solo pretendo dar a conocer un conjunto mural descubierto en el muro testero de la capilla mayor y restaurado en fechas recientes, sino también poner de manifiesto la singularidad del mismo, aspecto que radica en el amplio programa iconográfico que ha sido representado, pues en él se recogen diversas escenas relativas a la hagiografía de tres santos (San Bartolomé, Santa Lucía y San Antonio Abad). Así, de forma similar a los retablos aragoneses de advocación triple, cada ciclo narrativo, con sus episodios correspondientes, se organiza siguiendo la estructura de un retablo.

Palabras clave: Fompedraza; Pintura mural; Tardogótico; San Bartolomé.

\section{The late Gothic mural painting in the province of Valladolid: The church of Saint Bartholomew of Fompedraza}

\begin{abstract}
Through this article about the mural paintings of the church of Saint Bartholomew of Fompedraza, which is located in the east of the province of Valladolid, I not only aim to make known a mural painting discovered in the front wall of the chapel and recently restored, but also to demonstrate their uniqueness, which is shown in the extensive iconographic program that has been represented due to the different scenes related to the hagiography of three saints (Saint Bartholomew, Saint Lucy and Saint Anthony Abbot). Thus, similar to the triple Aragonese altarpieces advocation, each narrative cycle, with their corresponding events, is organized by following the structure of an altarpiece.
\end{abstract}

Key words: Fompedraza; Mural Painting; Late Gothic; Saint Bartholomew. 


\section{INTRODUCCIÓN ${ }^{1}$}

El estudio pormenorizado de las pinturas murales de la iglesia de San Bartolomé de Fompedraza, cuya restauración finalizó en 2009, pretendo que sirva para concienciarnos de los constantes descubrimientos que actualmente se están produciendo en el contexto de las restauraciones de templos religiosos, creando también una sensibilidad extensible a todas las fuerzas sociales hacia la puesta en valor de esta manifestación artística.

Además, mediante este conjunto mural, se pone de manifiesto la existencia de pintura mural tardogótica en este ámbito en concreto de Castilla y León, pues además de las de Fompedraza, hay que mencionar los conjuntos murales conservados en las cercanas localidades de Peñafiel, Castrillo de Duero, Sacramenia y Cuevas de Provanco, todas ellas ubicadas en el límite entre la provincia de Valladolid y Segovia.

\section{LA IGLESIA DE SAN BARTOLOMÉ}

Las pinturas murales se localizan en el muro testero de la capilla mayor de la iglesia de San Bartolomé de Fompedraza, cuyos orígenes se remontan al siglo XIII ${ }^{2}$. Así, a pesar de las diversas reformas y procesos constructivos a que ha sido sometida la iglesia a lo largo de los siglos XVI, XVII y XVIII ${ }^{3}$, cuyo resultado se aprecia tanto en la apariencia externa como en la interna del edificio, el muro testero así como la capilla mayor no han sufrido ninguna modificación a lo largo de la trayectoria histórica del edificio, pues este espacio, tal y como lo demuestra la bóveda de crucería simple que le cubre, pertenecería a la época primigenia del templo.

Con todo, la conservación de la capilla mayor, así como la decisión en el siglo XVIII de cubrir el testero con un retablo ${ }^{4}$, han permitido que el conjunto mural haya llegado en muy buen estado hasta nuestros días.

\section{ESTUDIO SOBRE LAS PINTURAS MURALES}

La singularidad del presente conjunto mural radica en el amplio programa iconográfico que ha sido representado, pues en él se recogen diversas escenas relativas a la hagiografía de tres santos (fig. 1). Cada ciclo narrativo, con sus respectivos epi-

1 El presente estudio forma parte del proceso de investigación orientado a la elaboración de la tesis doctoral titulada La pintura mural tardogótica en Castilla y León: provincias de Valladolid, Ávila, Segovia y Soria, cuya realización está siendo posible gracias a ser beneficiario de un contrato de personal investigador de reciente titulación universitaria financiado por la Consejería de Educación de la Junta de Castilla y León y el Fondo Social Europeo.

2 CASTÁN LANASPA, Javier, Arquitectura religiosa gótica en Valladolid y su provincia (s. XIII-XVI), Valladolid, Diputación provincial de Valladolid, 1998, p. 338.

3 VALDIVIESO, Enrique, Catálogo monumental de la provincia de Valladolid. Antiguo partido judicial de Peñafiel, Valladolid, Diputación Provincial de Valladolid, 1975, p. 96.

4 Ibid., p. 97. 


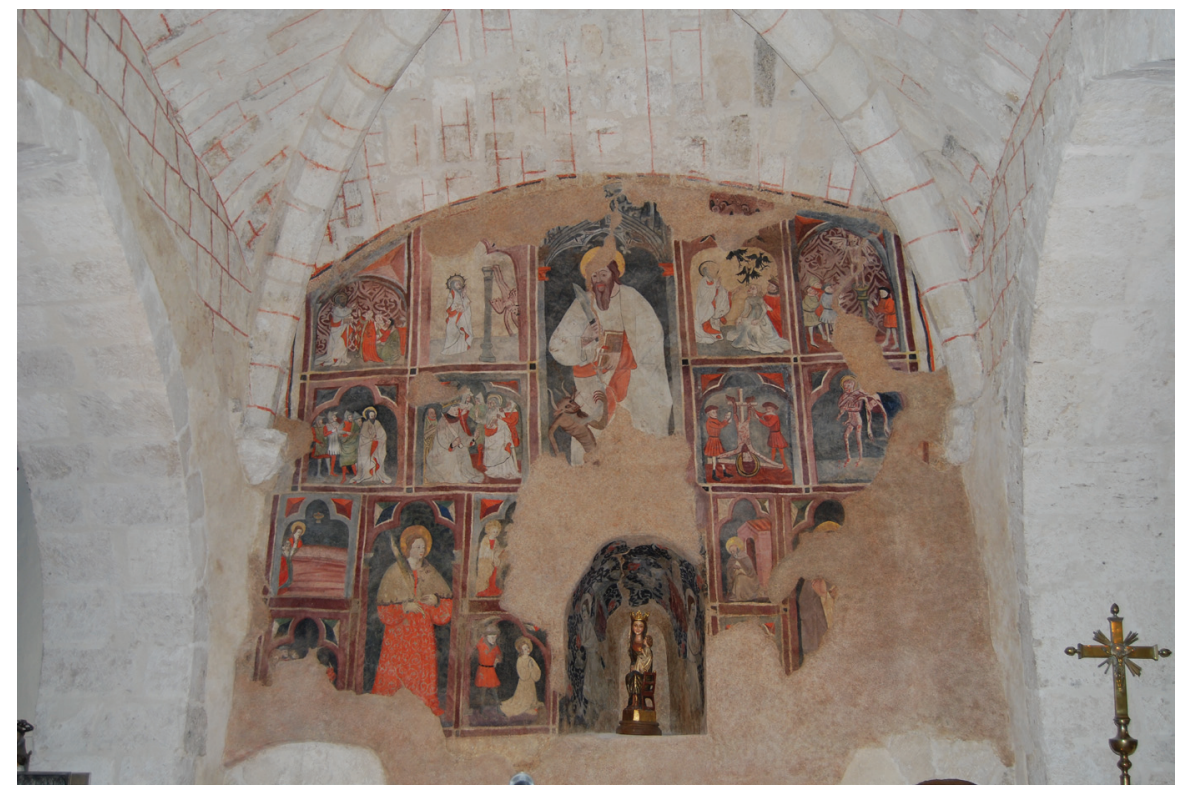

Fig. 1. Conjunto mural, h. 1470, pintura al temple, iglesia de San Bartolomé, Fompedraza, Valladolid (España).

sodios, se organiza siguiendo la estructura de un retablo, pues además de la calle central, donde se ubica la efigie del santo correspondiente, cuenta con sus calles y cuerpos superpuestos en los que se disponen diversos pasajes, los cuales se articulan, exceptuando las dos escenas situadas en los extremos del cuerpo superior del ciclo narrativo de San Bartolomé y la segunda comenzando por la derecha del mencionado cuerpo, que lo hacen mediante arco de medio punto y un arco semirrebajado respectivamente, por medio de un arco trilobulado.

Aunque esta organización es frecuente en otros conjuntos hispanos, entre los que se sitúan los retablos aragoneses de advocación triple (Retablo de San Blas, de la Virgen de la Misericordia y de Santo Tomás Becket de la iglesia parroquial de Anento de Zaragoza realizado por Blasco de Grañén o el Retablo de Santa Catalina, San Lorenzo y San Prudencio de la capilla de los Pérez Calvillo de la catedral de Tarazona ejecutado por Juan de Leví) $)^{5}$, en las pinturas murales de la iglesia de San Bartolomé de Fompedraza, al igual que en los retablos aragoneses anteriormente mencionados, cada ciclo mantiene una relativa independencia dentro del conjunto, por lo que, al final, es como si se combinaran tres retablos en un uno.

5 LACARRA DUCAY, María del Carmen, Blasco de Grañén, pintor de retablos (1422-1459), Zaragoza, Institución Fernando el Católico, Diputación de Zaragoza, 2004, pp. 111-154; LACARRA DUCAY, María del Carmen, "Juan de Leví, pintor al servicio de los Pérez Calvillo en su capilla de la Seo de Tarazona (14031408)", en VV.AA., Retablo de Juan de Leví y su restauración. Capilla de los Pérez Calvillo, catedral de Tarazona (cuadernos de restauración), Zaragoza, Diputación general de Aragón, 1990, pp. 27-46. 
El hecho de que el templo parroquial esté bajo la advocación de San Bartolomé influyó en la pretensión de otorgar al ciclo narrativo del santo un mayor protagonismo, estatus que consiguió mediante la disposición de su hagiografía en la parte más alta del conjunto mural y la representación de ocho escenas relativas a su vida distribuidas en cuatro calles y dos cuerpos. Por debajo de la hagiografía del santo apóstol y ocupando una posición central existe una hornacina que en origen debió de ser la ventana de iluminación del presbiterio, pues la presencia en su interior de dos ángeles (fig. 2), en este caso ceroferarios, es un convencionalismo utilizado en la ornamentación de los vanos durante el periodo medieval, aspecto que también se puede apreciar, aun siendo ángeles turiferarios, en las pinturas murales de la iglesia de San Clemente de Segovia ${ }^{6}$. A ambos lados de la hornacina, se ubica el ciclo de Santa Lucía (a la izquierda) y el de San Antonio Abad (a la derecha), los cuales cuentan con cuatro escenas distribuidas en dos calles y dos cuerpos.

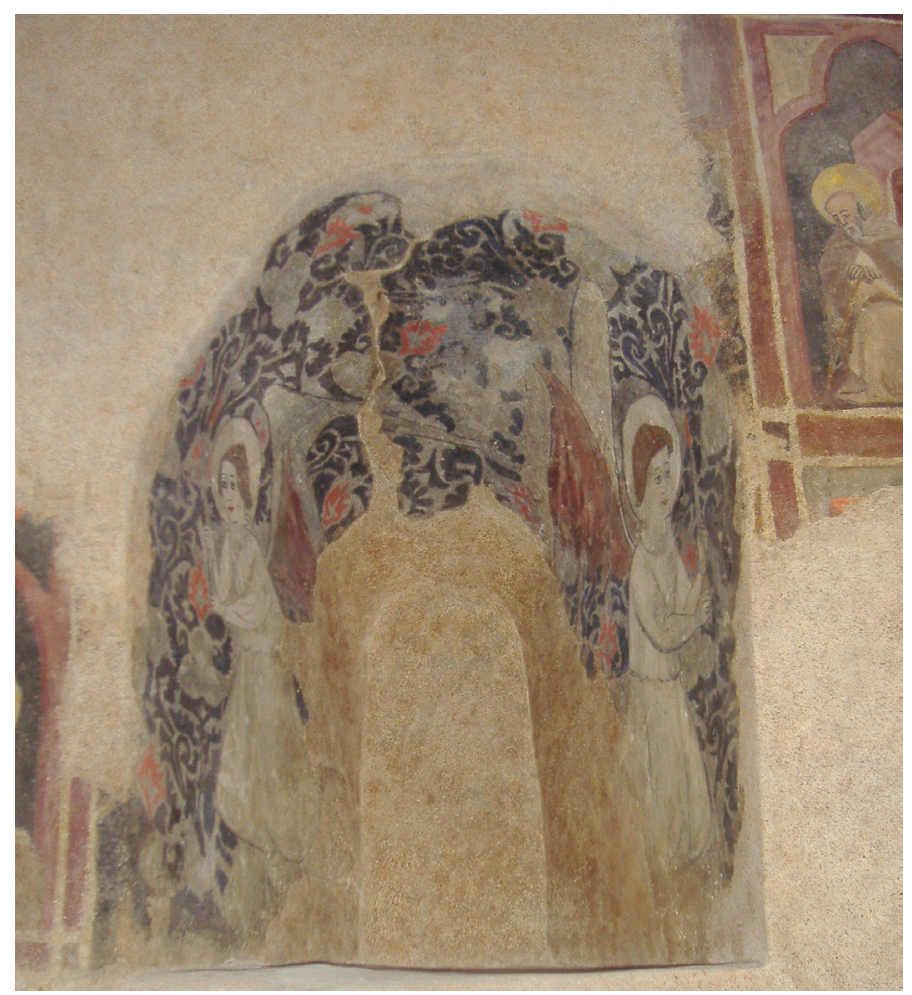

Fig. 2. Hornacina con ángeles ceroferarios, h. 1470, pintura al temple, iglesia de San Bartolomé, Fompedraza, Valladolid (España).

6 MANZARBEITIA, Santiago, "Las pinturas murales de la iglesia de San Clemente de Segovia", en Estudios Segovianos, $\mathrm{n}^{\circ}$ 87, 1990, pp. 309-312; AZCÁRATE LUXÁN, Matilde, Las pinturas murales de las iglesias de San Justo y San Clemente de Segovia, Segovia, Caja Segovia, 2002, pp. 119-120. 


\section{HAGIOGRAFÍA DE SAN BARTOLOMÉ}

En la calle central se sitúa la efigie del santo apóstol. Ataviado con túnica blanca y manto blanco por el anverso y rojo por el reverso, su fisonomía está influida por la descripción que realiza el ídolo Berith en La leyenda dorada ${ }^{7}$. Además, aparece con sus atributos personales: el cuchillo, con el que fue despellejado, en la mano derecha, aunque sin la piel, y un libro en la mano izquierda, el cual indica su condición de Apóstol ${ }^{8}$. A sus pies, y encadenado, se representa un demonio, cuya presencia procede del Evangelio Apócrifo de San Bartolomé9.

El ciclo narrativo de la leyenda de San Bartolomé lo conforman ocho escenas, cuyo orden de lectura correcto será de izquierda a derecha y de arriba abajo (fig. 3):

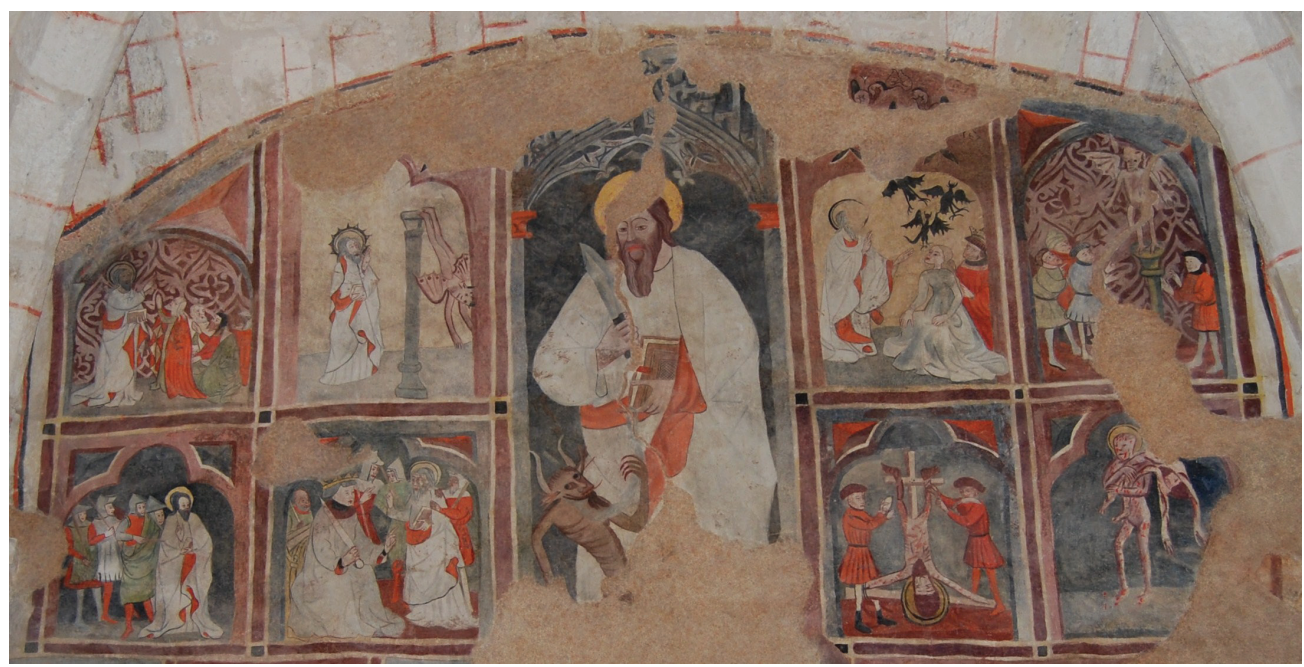

Fig. 3. Ciclo hagiográfico de San Bartolomé, h. 1470, pintura al temple, iglesia de San Bartolomé, Fompedraza, Valladolid (España).

\footnotetext{
7 "Es un hombre de estatura corriente, cabellos ensortijados y negros, tez blanca, ojos grandes, nariz recta y bien proporcionada, barba espesa y un poquito entrecana". Vid. VORÁGINE, Santiago de la, La leyenda dorada, tomo 2, Madrid, Alianza Editorial, 1982, p. 524

8 RÉAU, Louis, Iconografía del arte cristiano. Iconografía de los santos de la A-F, t. II, vol. 3, Barcelona, Ediciones del Serbal, 1997, p. 181.

9 "Al verle (a Belial) los apóstoles cayeron en tierra sobre sus rostros y quedaron como muertos. Mas Jesús se acercó a ellos y les infundió animo. Y dice a Bartolomé: "Písale con tu propio pié en su cerviz y pregúntale cuáles eran sus obras...”. Vid. REVILLA, Federico, Diccionario de Iconografía y Simbología, Madrid, Cátedra, 1999, p. 67.
} 
San Bartolomé libera a un endemoniado de la posesión diabólica en presencia de un grupo de enfermos (cuerpo superior, primera calle, comenzando por la izquierda).

Lo representado se justifica a partir del siguiente pasaje de La leyenda dorada: “...los enfermos buscaron afanosamente al siervo de Dios; pero por más empeño que pusieron en la búsqueda no lo hallaron por parte alguna. Un día cierto endemoniado gritó: "Bartolomé, apóstol de Dios, tus oraciones son como un fuego que me abrasa". Bartolomé respondió: " $¡ C a l l a$, y sal ahora mismo del cuerpo de ese hombre!" En aquel mismo momento el poseso quedó liberado" 10 .

San Bartolomé de pie y a la izquierda, se dirige con la mano derecha hacia un hombre, probablemente el enfermo, de barba y pelo blanco, arrodillado y vestido con un sayo verde cubierto con un manto rojo. Detrás de él se sitúan otros tres personajes arrodillados.

San Bartolomé arroja al suelo al ídolo del templo (cuerpo superior, segunda calle).

A pesar de la inexistencia de referencias textuales, esta escena se podría interpretar como la expulsión de los ídolos del interior de los templos abogada por el propio San Bartolomé, el cual se convierte en el auténtico defensor de la religión y la fe cristiana.

De acuerdo a esta interpretación, San Bartolomé con la mano izquierda derriba el ídolo situado en lo alto de una columna del templo. Muy interesante es la forma de representar el nimbo del santo, pues mientras que en todas las escenas éste es dorado, en este caso del nimbo surgen rayos, pretendiendo quizás destacar a la figura de San Bartolomé, no solo como apóstol de Dios, sino también como defensor de la doctrina cristiana frente al paganismo plasmado en el ídolo.

San Bartolomé libera a la hija de Polimio de los males que la afligían (cuerpo superior, escena a la derecha de la calle central).

Este episodio, también representado en las pinturas murales de la iglesia de Nuestra Señora de Arbas de Gordaliza del Pino (León) ${ }^{11}$, tiene su justificación en el pasaje de La leyenda dorada en el que se recoge la petición por parte del monarca Polimio hacia San Bartolomé para que éste curara a su hija endemoniada ${ }^{12}$.

San Bartolomé, a la izquierda de la escena, ha sido representado con la mano izquierda levantada y bendiciendo con la derecha, dirigiéndose hacia la hija del rey Polimio, quien está sentada con un vestido blanco por delante de su padre coronado. El instante en que la hija del monarca queda liberada de todos los males ha sido representado no sólo mediante tres pequeños demonios negros que, como símbolo del mal, tendrían forma de murciélago y estarían huyendo hacia el cielo, sino también mediante la presentación de la boca ligeramente entreabierta, sugiriendo así la expulsión de todos los males.

\footnotetext{
10 VORÁGINE, Santiago de la (1982), op. cit., p. 525.

11 GRAU LOBO, Luis A., "Murales góticos de la provincia de León: perfil a propósito de algunas novedades", en Brigecio, no 7, 1997, pp. 141-142.

12 VORÁGINE, Santiago de la (1982), op. cit., p. 525.
} 
Los pontifices del templo celebran un acto religioso en el templo (cuerpo superior, cuarta calle).

Lo representado en el registro refleja el pasaje de La leyenda dorada en que los pontífices celebrando un acto religioso en el templo son increpados por el propio ídolo cuando le estaban ofreciendo sacrificios en su honor: “¡No sigáis adorándome si no queréis padecer tormentos aún más terribles que los que yo estoy padeciendo! ¡Sabed que me encuentro atado y reatado con ligaduras de fuego y que he sido puesto en la situación en que me veo por un ángel de aquel Jesucristo a quien los judíos crucificaron creyendo que al darle muerte en la cruz quedaría muerto para siempre (...)"13.

Siguiendo lo indicado, en el centro de la composición se encuentra el ídolo, quien representado con alas y garras, está situado en lo alto de una columna. Los personajes que rodean al ídolo (tres a la izquierda y otro más a la derecha), podrían ser identificados con los pontífices del templo, puesto que su indumentaria haría referencia a su pertenencia a una jerarquía superior.

Si bien las escenas anteriormente analizadas aluden al Ciclo de la Predicación de San Bartolomé, las que se exponen a continuación hacen referencia al Ciclo de la Pasión del santo:

El Prendimiento de San Bartolomé (primer cuerpo, primera calle comenzando por la izquierda).

Tras ser curada la hija de Polimio y recibir éste la doctrina cristiana por parte de San Bartolomé, el monarca renunció al trono convirtiéndose en discípulo del apóstol. El nuevo monarca Astiages, enterado de la destrucción de los ídolos promovida por el santo apóstol, ordenó prender a San Bartolomé ${ }^{14}$.

Esta escena no aparece única y exclusivamente en el ciclo de San Bartolomé perteneciente al conjunto mural que está siendo objeto de interés, sino que también se puede apreciar en las pinturas murales de la capilla de San Bartolomé de Villalba de Peregiles (Zaragoza) ${ }^{15}$.

San Bartolomé ante el rey Astiages (primer cuerpo, segunda calle). Tras haber sido prendido por los soldados y llevado a palacio, San Bartolomé aparece ante Astiages.

El monarca y el santo apóstol se convierten en los auténticos protagonistas de la escena, pues mientras que el resto de las figuras han sido representadas en un segundo plano, estos dos personajes aparecen en primer plano y a un mayor tamaño. La figura del monarca destaca especialmente al estar sentada, posición reservada para las grandes dignidades y personalidades, pues otorgaba una consideración de privilegio, poniendo de manifiesto su autoridad. Astiages, a la izquierda de la composición, va ataviado con un amplio manto, tocado con una corona y con una

13 Ibid., p. 526.

14 Ibid., p. 526.

15 LACARRA DUCAY, María del Carmen, "Pinturas murales góticas de origen aragonés en Sitges (Barcelona): la capilla de San Bartolomé de Villalba de Peregiles (Zaragoza)", en Artigrama, n 12, 1996-97, p. 365. 
espada en la mano derecha, símbolo de justicia en la Edad Media ${ }^{16}$, mientras que con la mano izquierda se dirige al propio San Bartolomé. Éste con la mano izquierda sujeta el libro mientras que con la mano derecha alza la mano dirigiéndose al monarca Astiages. Por detrás de San Bartolomé se sitúan dos soldados hablando entre ellos mientras que un tercero aparece sujetando al santo apóstol. Por detrás del monarca se ubica un escribano quien estaría dando fe de la conversación de los dos personajes protagonistas.

La crucifixión y el desollamiento de San Bartolomé (primer cuerpo, cuarta calle).

El artista ha combinado dos formas de martirio en una sola escena, pues el santo apóstol, al tiempo que está siendo desollado, aparece crucificado a la inversa, lo cual respondería a la tradición oriental. Ciertamente, ambos martirios son complementarios y su representación llegó a adquirir una gran fortuna en los ciclos narrativos dedicados a San Bartolomé, pues de la misma que en Fompedraza, esta misma temática aparece en el fragmento del Retablo de San Bartolomé del Museo de Tarrasa ${ }^{17}$ y en las pinturas murales de la Capilla de San Bartolomé procedentes de Villalba de Perejiles (Zaragoza) ${ }^{18}$, aunque en ese caso el santo no está crucificado a la inversa. Por lo tanto, San Bartolomé, crucificado a la inversa y desnudo, aparece con todo su cuerpo cubierto completamente de heridas, haciendo referencia a la flagelación previa. Al tiempo, dos personajes flanqueando la cruz efectúan el desollamiento del santo.

San Bartolomé llevando su piel a cuestas (primer cuerpo, quinta calle).

El santo apóstol aparece llevando su piel, atributo en el que se ha reflejado su rostro barbado, y con el que se cubre su cuerpo en carne en viva, lo que indica su desollamiento previo.

\section{HAGIOGRAFÍA DE SANTA LUCÍA}

Ésta se organiza también a modo de retablo formado por una calle central y dos calles laterales organizadas en dos cuerpos superpuestos (fig. 4).

En la calle central se representa la efigie de Santa Lucía, quien viste una larga túnica roja decorada con roleos blancos, encima de la cual lleva un mantonina. Además de con el nimbo dorado, aparece con dos de sus atributos característicos: en la mano derecha, la palma de martirio; mientras que con la mano izquierda sostiene, aunque prácticamente perdido, un cáliz, en cuyo interior se sitúan sus ojos ${ }^{19}$.

16 REVILLA, Federico (1999), op. cit., p. 167.

17 MELERO-MONEO, Marisa, La pintura sobre tabla del gótico lineal: frontales, laterales de altar y retablos en el reino de Mallorca y los condados catalanes, Bellaterra, Universidad Autónoma de Barcelona, 2005, p. 165.

18 LACARRA DUCAY, María del Carmen (1996-97), op. cit., p. 366.

19 CARMONA MUELA, Juan, Iconografia de los santos, Madrid, Ed. Istmo, 2008, p. 292. 


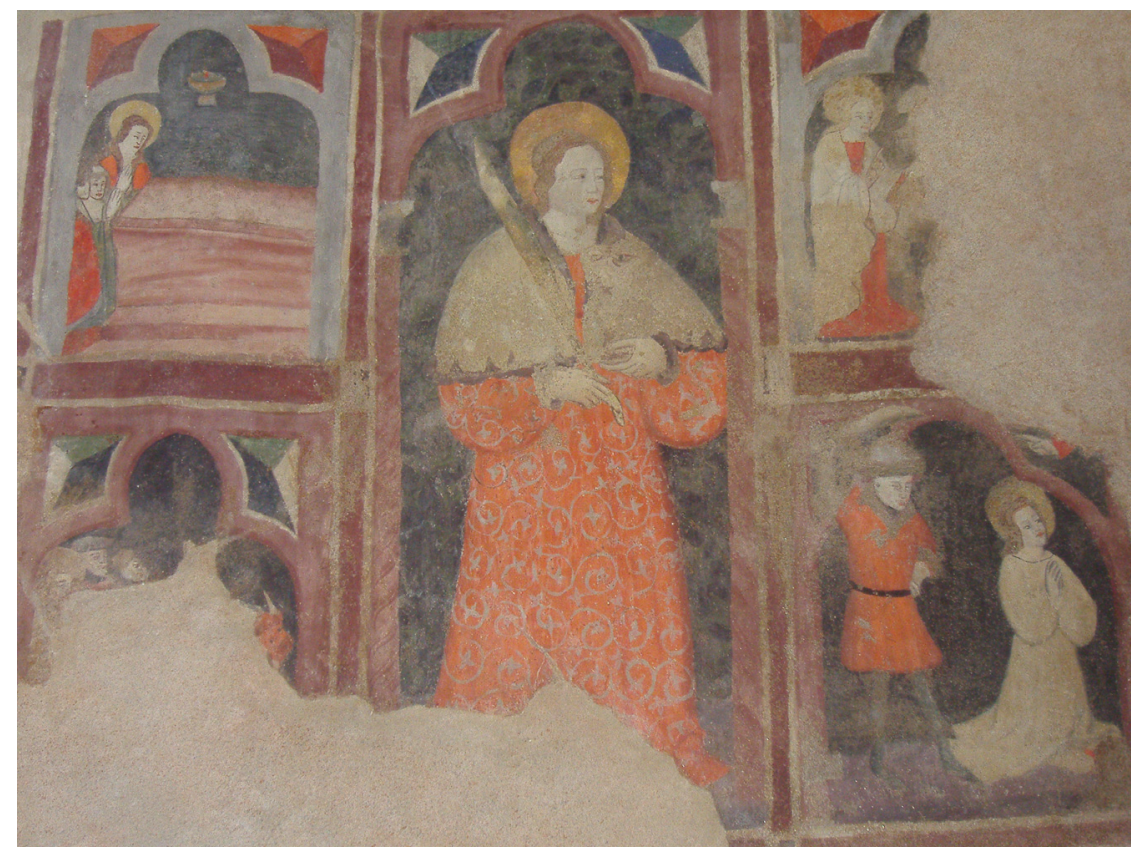

Fig. 4. Ciclo hagiográfico de Santa Lucía, h. 1470, pintura al temple, iglesia de San Bartolomé, Fompedraza, Valladolid (España).

El ciclo hagiográfico de Santa Lucía se compone de cuatro pasajes cuya correcta lectura es de izquierda a derecha y de arriba abajo:

Santa Lucía y Eutaquia rezan ante el sepulcro de Santa Águeda (calle izquierda, segundo cuerpo).

Lo representado tiene que ver con la peregrinación que Santa Lucía y su madre, Eutaquia, realizaron al sepulcro de Santa Águeda ${ }^{20}$.

La escena está protagonizada por el sepulcro de Santa Águeda, ante el que Santa Lucía, al fondo y con el nimbo dorado, y Eutaquia en primer plano y aparentando una edad más avanzada, aparecen arrodilladas y con las manos juntas en actitud de rezo. Por encima del sepulcro se ha representado una luminaria, permitiendo ubicar el pasaje en un interior.

La visión de Santa Águeda por parte de Santa Lucía (calle derecha, segundo cuerpo). El origen de esta escena proviene de la visión que, en un sueño, Santa Lucía tuvo de Santa Águeda ${ }^{21}$.

20 VORÁGINE, Santiago de la, La Leyenda Dorada, tomo I, Madrid, Alianza Editorial, 1984, p. 44.

21 Ibid., p. 44. 
Aunque sólo se conserva una figura, ésta se identificaría con Santa Águeda, puesto que además de llevar el nimbo dorado, elemento que descarta a Eutaquia, sus rasgos faciales y el tono blanquecino del cabello no se corresponden con la anterior imagen de Santa Lucía. Esta identificación también es posible gracias a la conservación de un elemento que sirve para recalcar la existencia de una conversación entre dos figuras, quizás el referido en la fuente textual: una mano que, perteneciente a una figura perdida, tiene un gesto similar al de la mano derecha de Santa Águeda, gesto que indicaría el diálogo entre ambas figuras.

Santa Lucía es arrastrada en vano por una serie de bueyes (primera calle, primer cuerpo).

La representación de esta escena supone un salto en su hagiografía, pues no narra que Pascasio, su prometido, al enterarse de que el dinero reservado para la dote del matrimonio iba destinado a obras piadosas y de caridad y no a negocios lucrativos, denunció a Santa Lucía ante el cónsul acusándola de su acercamiento a la doctrina cristiana. El cónsul la obligó a rendir culto a dioses paganos pero no pudieron moverla del sitio, razón por la cual, el cónsul llamó a mil hombres quienes "fueron sustituidos por mil parejas de bueyes" 22 . Aunque la figura de la santa no se conserva, sí que lo ha hecho la cabeza de uno de los bueyes y tres figuras en la izquierda del registro, lo que ha permitido identificar esta escena con el pasaje señalado.

La decapitación de Santa Lucía (calle derecha, primer cuerpo).

Al no poder ser movida ni por una yunta de bueyes ni por magos, fue sometida a una serie de tormentos (la rociaron con orina hirviendo, plomo fundido en las orejas, le arrancaron los dientes y los pechos e incluso se levantó una hoguera) ${ }^{23}$, pero al comprobar que la santa seguía sin estar dispuesta a abandonar la doctrina cristiana en pro del paganismo, "atravesaron con una espada la garganta de Santa Lucía"24.

Santa Lucía, ataviada con una amplia túnica y con el nimbo dorado, se encuentra en actitud de rezo, pues está arrodillada y con las dos manos unidas. A su derecha se representa el verdugo que va a efectuar la ejecución de la santa, en cuya mano derecha sostiene la espada. Todo el conjunto se completa con la presencia de una mano bendiciendo en la enjuta derecha del arco trilobulado que enmarca la escena. Esta mano se identifica con la dextera Dei, concebida como "señal de recepción del sacrificio del santo" 25 .

22 Ibid., p. 45.

23 RÉAU, Louis, Iconografía del arte cristiano. Iconografía de los santos de la G-O, t. II, vol. 4, Barcelona, Ediciones del Serbal, 1997, p. 268.

24 VORÁGINE, Santiago de la (1984), op. cit., p. 46.

25 GUTIÉRREZ BAÑOS, Fernando, Aportación al estudio de la pintura de estilo gótico lineal en Castilla y León: Precisiones cronológicas y corpus de pintura mural y sobre tabla, tomo II, Madrid, Fundación universitaria española, 2005, p. 273. 


\section{HAGIOGRAFÍA DE SAN ANTONIO ABAD}

Si bien el análisis de este ciclo narrativo se encuentra condicionado por la pérdida de parte de la superficie pictórica que impide un estudio en profundidad del mismo, por los restos que se han conservado, es muy probable que las diferentes escenas se organizaran siguiendo el sistema articulador empleado en el ciclo hagiográfico de Santa Lucía.

Como en los casos anteriores, en la calle central se sitúa, aunque muy perdida, la efigie de San Antonio Abad. La fisonomía del mismo ha podido ser reconstruida a partir de la figura del santo eremita que aparece en la única escena del ciclo que se conserva. Así, la efigie de San Antonio Abad se correspondería con la forma más habitual de representarlo, es decir, como un anciano, de larga barba, con un nimbo dorado sobre la cabeza y ataviado con una túnica blanca y sayal con capucha de color pardo, prenda característica de un monje antoniano. Con la mano derecha sujeta el bastón terminado en forma de tau, cuyo origen se remonta al mundo egipcio, identificado con el arma utilizada por Dios contra los demonios, haciendo referencia a las tentaciones en el desierto ${ }^{26}$. No es posible saber si el cerdo, la esquila o las llamas del fuego de San Antonio fueron representados junto a la figura del santo.

La única escena conservada se correspondería con San Antonio Abad en el desierto haciendo vida eremítica (calle izquierda, segundo cuerpo), episodio que hace referencia al instante en que San Antonio Abad, tras desprenderse por completo de sus riquezas, debido a la influencia de unas palabras realizadas por un predicador, "se retiró al desierto para hacer vida eremítica“"27.

El santo, ataviado según la descripción recogida anteriormente, sostiene con las dos manos el característico bastón en forma de tau griega. Por detrás de él se ha situado una construcción, cuya representación, aun no existiendo una correspondencia entre las proporciones del edificio y la figura del santo, indica un conocimiento de la perspectiva.

Muy probablemente, por el tema representado y por las similitudes en la disposición de las escenas al ciclo de Santa Lucía, este pasaje sería el inicio de la hagiografía del santo eremita, siendo posible, y tomando como referencia las fuentes así como los diversos conjuntos pictóricos que narran la vida de San Antonio, establecer lo que en origen pudo representarse en el resto de las escenas. En este sentido, cabe destacar que la devoción hacia santos que rechazan los placeres mundanos llevando una vida de penitencia y de ascetismo adquirió una gran popularidad durante los siglos de la Baja Edad Media, al igual que los pasajes con presencia del demonio, pues las representaciones venciendo al diablo cumplieron con la función de acentuar la piedad al santo y de fortalecer el espíritu de los creyentes a través de la victoria sobre el demo$n^{28}{ }^{28}$. Por ello, entre las escenas más representadas está la de San Antonio tentado por

\footnotetext{
26 GARCÍA PÁRAMO, Ana María, Aportaciones al estudio de la iconografía de los Santos en el Reino de Castilla, Madrid, Ed. Universidad Complutense, 1988, p. 261.

27 VORÁGINE, Santiago de la (1984), op. cit., p. 107.

28 NUET BLANCH, Marta, "San Antonio tentado por la lujuria. Dos formas de representación en la pintura de los siglos XIV y XV", en Locus Amoenus, n² 2, 1996, p. 124.
} 
un demonio en figura de hermosa mujer o aquellas en las que San Antonio está siendo apaleado por los demonios o San Antonio arrebatado en los aires por los demonios ${ }^{29}$.

\section{REFERENTES CRONOLÓGICOS}

Para determinar de la manera más precisa posible la cronología de las pinturas murales situadas en el testero de la capilla mayor puede resultar especialmente útil el análisis de la indumentaria de los personajes que componen las escenas cuya vestimenta se ajusta a la evolución de la moda, aunque existen un conjunto de inconvenientes motivados por la simplificación y ausencia de detalles con que los atavíos han sido representados, lo cual es fruto, con toda probabilidad, de la falta de habilidad del artista.

Entre las prendas representadas con una mayor asiduidad están el jubón y la jaqueta, pues con ellas están ataviados tres de los cuatro personajes de la escena en que Los pontifices del templo celebran un acto religioso y los dos sayones de la Crucifixión y el desollamiento del santo apóstol, ambas pertenecientes al ciclo de San Bartolomé. También con esta indumentaria va ataviado el verdugo que atraviesa con una espada la garganta de Santa Lucía.

El surgimiento del jubón y de la jaqueta se produjo en el último tercio del siglo XIV, aunque antes de 1370 , constituyéndose en prendas características de la moda del último tercio del siglo XIV, moda que, inspirada en los nuevos ideales artísticos procedentes del estilo gótico internacional, se caracterizó por la búsqueda de los contrastes entre siluetas recortadas y ampulosas e incluso existe un interés por subrayar ciertas partes y borrar otras ${ }^{30}$, a lo que contribuyen el jubón y la jaqueta. No obstante, la jaqueta del pontífice situado a la derecha del pasaje titulado Los pontifices del templo celebran un acto religioso y, en especial, las que llevan los dos sayones en el episodio de la Crucifixión y el desollamiento de San Bartolomé (fig. 5), contienen una serie de rasgos propios del estilo borgoñón o francés, el cual, surgido en la prestigiosa corte de los duques de Borgoña en Francia en la década de 1420, se convertirá en la principal inspiración del traje masculino español desde la década de los 50 hasta la de los setenta aproximadamente ${ }^{31}$. Este gusto franco-borgoñón se basaba en el empleo de estas prendas, pues permitían la creación de intensos contrastes entre hombros anchos y una cintura estrecha, pretendiendo con ello alcanzar el ideal de elegancia masculina. Además, la abundancia de pliegues verticales y regulares reafirma el citado ideal, pues ésta, contribuye a subrayar la verticalidad y la esbeltez de la figura.

Aunque la moda franco-borgoñona se caracterizaba por tocados muy desarrollados, como por ejemplo los bonetes en forma de cono truncado e incluso el capirote de rollo, el menor desarrollo del tocado aquí representado enlaza con las innovaciones

29 RÉAU, Louis, Iconografía del arte cristiano. Iconografia de los santos de la A-F, t. II, vol. 3, Barcelona, Ediciones del Serbal, 1997, pp. 116-120.

30 SIGÜENZA PELARDA, Cristina, La moda en el vestir en la pintura gótica aragonesa, Zaragoza, Institución Fernando el Católico, Diputación de Zaragoza, 2000, p. 162.

31 BERNIS, Carmen, Trajes y modas en la España de los Reyes Católicos. Los Hombres, tomo II, Madrid, Instituto Diego Velázquez (CSIC), 1979, p. 35. 


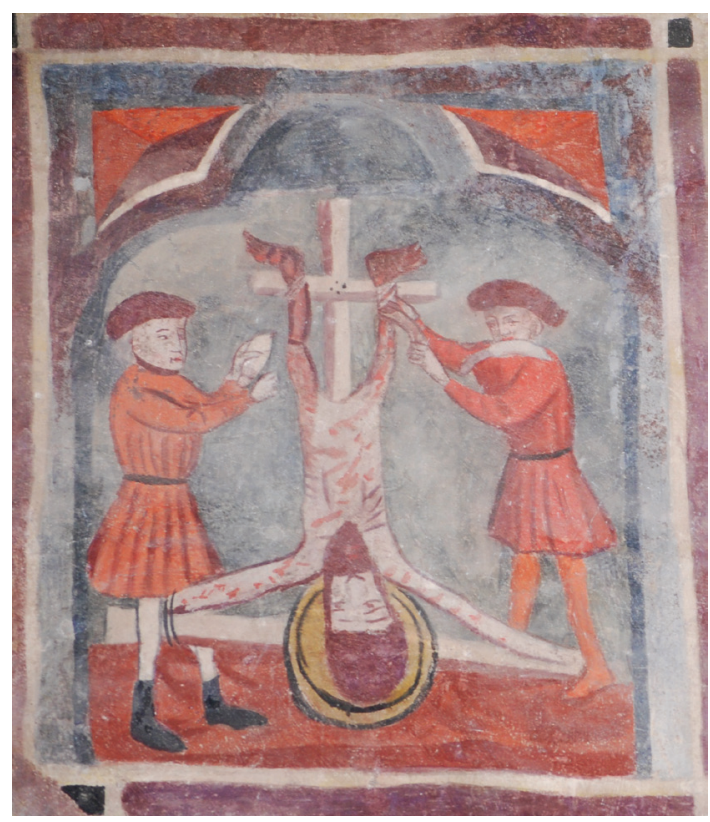

Fig. 5. Los sayones ataviados con jaquetas en la crucifixión y el desollamiento de San Bartolomé, h. 1470, pintura al temple, iglesia de San Bartolomé, Fompedraza, Valladolid (España).

que se introdujeron en la moda a partir de la década de los 70 del siglo XV, época en la que se imponen los tocados pequeños y redondos ${ }^{32}$. En contraste, el tocado con el que va ataviado uno de los personajes en la escena en la que Los pontifices del templo celebran un acto religioso se corresponde con una toca morisca, también conocida como turbante ${ }^{33}$. Ésta consiste en una pieza de tela, larga y estrecha, que se enrollaba a la cabeza, cuya presencia es más bien propia de la segunda mitad del siglo XV, momento en el que se estilaron, fruto de la atracción hacia la civilización musulmana del reino de Granada ${ }^{34}$, este tipo de tocados de origen musulmán.

El análisis del armamento también será de utilidad en relación a la aproximación cronológica del conjunto mural.

La representación del armamento se reduce a los soldados que aparecen reflejados en dos escenas, concretamente en la del Prendimiento de San Bartolomé y en la del Santo apóstol ante el rey Astiages. Aunque sin escudo, éstos aparecen fundamentalmente constituidos por el armamento defensivo, compuesto por casco y defensas corporales, pues el escaso detallismo con que ha sido representado el armamento ofensivo impide realizar un estudio exhaustivo del mismo.

\footnotetext{
32 BERNIS MADRAZO, Carmen, Indumentaria medieval española, Madrid, Instituto Diego Velázquez (CSIC), 1956, p. 47.

33 SIGÜENZA PELARDA, Cristina (2000), op. cit., p. 155.

34 BERNIS, Carmen (1979), op. cit., p. 20.
} 
Comenzado con el análisis del casco, hay que indicar que todos los soldados cubren su cabeza con el citado componente. Este yelmo se trata de un bacinete, casco compuesto esencialmente por dos elementos: una estructura cerrada que protege la nuca y toda la cabeza a excepción de la cara, teniendo un perfil bastante apuntado con la intención de contrarrestar los golpes, y una vista móvil que protege la cara ${ }^{35}$, elemento solo visible en el bacinete del segundo soldado comenzado por la izquierda de la escena del Prendimiento de San Bartolomé y quizás, aunque no con toda seguridad, en uno de la escena en que San Bartolomé se presenta ante el rey Astiages. El bacinete se ensamblaría al gorjal, componente que tenía como misión proteger el cuello, las clavículas y la barbilla. Este elemento se ve perfectamente en el soldado situado a la izquierda de la escena del Prendimiento de San Bartolomé.

El uso de este componente responde a la complicación que estaba adquiriendo el armamento ofensivo a partir de mediados del siglo XIV ${ }^{36}$, por lo que su presencia permite indicar que estas pinturas murales han sido realizadas en una fecha bastante avanzada dentro de la Edad Media. El bacinete se constituye en el más claro correlato en la cabeza de las piezas de arnés ${ }^{37}$, cuyo surgimiento también responde a la complejidad que el armamento estaba protagonizando. Aunque las planchas de hierro o de acero forjado que cubrían todo el cuerpo con las correspondientes articulaciones en los brazos (guardabrazos, brazales, manoplas, escarcelas) y en las piernas (quijotes, rodilleras, grebas y escarpes) no llegaron a ser representadas ${ }^{38}$, sí que aparece, en el soldado que está atacando a San Bartolomé en la escena del Prendimiento del santo apóstol, uno de los elementos más característicos del arnés gótico: el peto.

\section{CONCLUSIÓN: FASES DE LA REALIZACIÓN Y CARACTERES ESTILÍSTICOS}

Los rasgos de la indumentaria y del armamento no solo permiten situar las pinturas murales en el siglo XV sino que también sirven para descartar la correspondencia de este conjunto mural al siglo XIV, tal y como queda recogido en la memoria de restauración $^{39}$. Esta adscripción puede deberse al aire tan retardatario que estas pinturas murales reflejan, quizá por su situación en un ámbito rural y secundario, hecho que se pone de manifiesto en el uso de forma sistemática del arco trilobulado enmarcando los diferentes encasamentos o en el tipo de arco, con rasgos goticistas y retardatarios más propios del siglo XIV, bajo el que se sitúa la efigie de San Bartolomé.

En primer lugar, la pertenencia de este conjunto mural al siglo XV podría justificarse por las formas triangulares que se ubican en las enjutas de los arcos trilobulados, formas

35 SOLER DEL CAMPO, Álvaro, La evolución del armamento medieval en el reino castellano-leones y Al-Andalus (siglos XII-XIV), Madrid, Editorial de la Universidad Complutense, 1991, pp. 334-335.

36 Ibid., p. 352.

37 GUTIÉRREZ BAÑOS, Fernando, Aportación al estudio de la pintura de estilo gótico lineal en Castilla y León: Precisiones cronológicas y corpus de pintura mural y sobre tabla, tomo I, Madrid, Fundación universitaria española, 2005, p. 315.

38 SOLER DEL CAMPO, Álvaro (1991), op. cit., p. 113.

39 Informe final de la restauración de las pinturas murales del ábside de la iglesia de Fompedraza. Restaurograma Hispania S.L., p. 4. 
también presentes en conjuntos murales correspondientes al periodo tardogótico como, por ejemplo, en la bóveda del presbiterio de la iglesia parroquial de San Cornelio y San Cipriano en San Cebrián de Mudá, realizada h. 1485-1490 40 , y en el arco de separación del cuarto de esfera absidal y la bóveda del presbiterio de la iglesia de San Juan Bautista de Fresno el Viejo, ejecutado entre la década de los sesenta y setenta del siglo $\mathrm{XV}^{41}$.

En segundo lugar, los elementos arqueológicos no solo ubican el conjunto mural en el siglo XV, sino que también me permiten realizar una mayor precisión cronológica, pues las particularidades estilísticas de las jaquetas, con rasgos de la moda franco-borgoñona, y la presencia de tocados ajenos al citado estilo y característicos más bien de la moda que se impuso en el período entre el reinado de Enrique IV y los Reyes Católicos, me permitirían situar el conjunto mural en torno a los años 70 del siglo XV.

Aunque por la cronología estas pinturas murales podrían tener relación con el estilo hispanoflamenco, los rasgos y elementos plasmados en el conjunto mural las sitúan más en la órbita del estilo gótico internacional, el cual se desarrolla entre las últimas décadas del siglo XIV y las primeras del siglo XV, aunque en Castilla penetra con posterioridad ${ }^{42}$. La vinculación con este estilo no sólo viene determinada por el interés en reflejar el ambiente cortesano por medio de trajes delicados y exóticos, visible en las jaquetas; sino también en un cierto conocimiento del manejo de la perspectiva, patente en la manera en que ha sido representado el edificio en el pasaje en el que San Antonio Abad está haciendo vida eremítica, además de por el gusto existente hacia la plasmación de elementos anecdóticos y secundarios, como el escribano de la escena en que San Bartolomé se presenta ante el rey Astiages.

A pesar de situarse en la órbita del estilo gótico internacional en fechas tan avanzadas, estas pinturas murales son bastantes arcaicas, pues incluso perviven rasgos del estilo gótico lineal, como el empleo de colores monocromos, una paleta de color bastante limitada en las fechas en las que fue realizado y por el uso de la línea que, en ocasiones se recrea en ritmos curvilíneos y amanerados, como elemento definidor de las figuras y de los diversos objetos representados, características, que recuerdan a las pinturas murales de Fresno el Viejo y ponen de manifiesto el creciente proceso de marginalización sufrido por la pintura mural desde finales del siglo XIV, debido a que la vanguardia pictórica pasó definitivamente a la pintura sobre tabla.

Su realización coincide pues, con los inicios del estilo hispanoflamenco en la provincia de Valladolid, el cual se desarrolló durante la segunda mitad del siglo XV y las primeras décadas del siglo XVI ${ }^{43}$. No obstante, es imposible situar este conjunto mural dentro de este estilo debido no sólo a una ausencia de la plasmación de la realidad inmediata de una forma minuciosa, sino además a la representación de los elementos arquitectónicos de una forma poco detallista. Además, no sólo no existe una individualización de los personajes, sino que se percibe una evidente ausencia de expresividad.

40 MANZARBEITIA VALlE, Santiago, La pintura medieval en torno al Alto Campoo, Palencia, Institución Tello Téllez de Meneses, Diputación de Palencia, 2001, p. 170.

41 NÚÑEZ MORCILLO, Sergio, "La pintura mural del siglo XV en Valladolid: Iglesia parroquial de Fresno el Viejo", en Anales de Historia del Arte (en prensa).

42 CAAMAÑO MARTÍNEZ, Jesús María, "La pintura gótica en Castilla la vieja y León”, en VV.AA.: Ciclo de conferencias sobre el gótico en Castilla y León, Palencia, 1984, p. 45.

43 Ibid., p. 49. 